\title{
As mulheres na ciência brasileira: crescimento, contrastes e um perfil de sucesso
}

\author{
JACQUELINE LETA
}

$\mathrm{H}$

ISTO RICAMENTE, a ciência sempre foi vista como uma atividade realizada por homens. D urante os séculos XV, XVI e XVII, séculos marcados por diversos eventos e mudanças na sociedade que possibilitaram o surgimento da ciência que conhecemos hoje, al gumas poucas mulheres aristocráticas exerciam importantes papéis de interlocutores e tutores de renomados filósofos naturais e dos primeiros experimentalistas. $\mathrm{N}$ ão obstante suas qualidades e competências, não Ihes era permitido o acesso às intensas e calorosas discussões que aconteciam nas sociedades e academias científicas, que se multiplicaram no século XVII por toda a Europa e tornaram-se as principais instituições de referência da ainda reduzida comunidade científica mundial. No século XVIII, essa situação pouco se modificou e o acesso das mulheres a essa atividade, com poucas exceções, deveu-se principalmente à posição familiar que elas ocupavam: se eram esposas ou filhas de algum homem da ciência podiam se dedicar aos trabalhos de suporte da ciência, tais como, cuidavar das coleções, limpar vidrarias, ilustrar e/ ou traduzir os experimentos e textos. 0 século seguinte é marcado por ganhos modestos no acesso de mulheres às atividades científicas, como a criação de colégios de muIheres, mesmo assim, elas permaneceram às margens de uma atividade que cada vez mais se profissionalizava. A mudança nesse quadro inicia-se somente após a segunda metade no século XX, quando a necessidade crescente de recursos humanos para atividades estratégicas, como a ciência, o movimento de liberação feminina e a luta pela iguald ade de direitos entre homens e mulheres permitiram a elas o acesso, cada vez maior, à educação científica e à carreiras, tradicionalmente ocupadas por homens ${ }^{1}$.

\section{O s estudos sobre as mulheres na ciência}

A primeira obra mais detalhada sobre a participação e realização de mulheres na ciência foi Women in Science, escrita, em 1913, por H . J. M ozans, um padre católico. Segundo Schienbinger (2001) essa obra convidava "as mulheres a atuarem no empreendimento científico e desencadearem as energias de metade da população do planeta". A partir daí, a literatura sobre gênero na ciência cresceu, ainda de forma incipiente, até os anos de 1970, ganhando destaque e importância entre os acadêmicos, principalmente, a partir dos anos de 1980. Anali- 
sada e discutida por estudiosos de diferentes áreas, sejam eles historiadores, sociólogos, biólogos, críticos culturais e filósofos e historiadores da ciência, essa temática torno-se em pouco tempo uma linha de pesquisa de múltiplas abordagens. Além disso, importante mencionar o papel de órgãos internacionais tal como a da U nesco que, desde a década de 1990, vem realizando estudos, pesquisas e, também, atividades, tal como conferências, que visam a discutir e a propor ações para a maior inclusão das mulheres nas atividades de ciência e tecnologia ( $C \& T$ ).

D entre os primeiros estudos publicados em periódicos científicos está o de Alice Rossi (R ossi, 1965). Publicado em uma das mais respeitosas revistas científicas do mundo, a Science, o artigo discute a participação de mulheres trabalhando em atividades de $C \&$ T nos Estados U nidos, nos anos de 1950 e 1960. Os dados desse estudo mostraram uma participação muito reduzida de mulheres empregadas em atividades de $C \& T$ em algumas áreas: nas engenharias, elas representavam cerca de $1 \%$ do total de empregados; já nas ciências naturais a participação delas foi de aproximadamente 10\% oscilando entre 5\% na física e $27 \%$ na biologia. Diante desse quadro, a autora discutia o papel de alguns aspectos sociais e/ ou psicológicos que poderiam explicar a baixa participação de mulheres em $C \& T$ naquele país, são eles: (a) a prioridade do casamento e da maternidade diante da escolha profissional, (b) a influência dos pais na escolha da carreira de seus filhos, determinando o que devem ser atitudes e comportamentos " femininos" e "masculinos" e (c) incompatibilidades ou diferenças de cunho biológico e/ ou social entre homens e mulheres, tal como nas habilidades cognitivas, na questão da independência, de persistência e do distanciamento do convívio social.

$\mathrm{N}$ ão obstante 0 fato de retratarem um quadro dos anos de 1960, esses mesmos aspectos aparecem, com maior ou menor destaque, na maior parte da literatura mundial sobre gênero na ciência que tem sido publicada desde então. A lém desses, outros aspectos também aparecem freqüentemente nessa literatura, tais como: cientistas do sexo feminino quando comparado com os cientistas do sexo masculino, em geral, (a) têm desempenho/ produtividade inferior, (b) têm menor acesso aos altos cargos acadêmicos, (c) recebem recursos menores para pesquisa e (d) recebem salários mais baixos. O bviamente, as causas para tamanhas diferenças e discrepâncias são muito complexas e envolvem múltiplos fatores, sejam eles de ordem social, cultural ou econômica².

Em relação à literatura brasileira sobre essa temática vale dizer que ela ainda é incipiente e, em geral, de difícil acesso e muito dispersa. D ados sistemáticos como os citados anteriormente não existem para o Brasil. Segundo L opes (1998), ainda há muito trabalho para ser feito no Brasil, começando por uma sistematização do que existe (publicado) sobre o tema, numa área de estudos que, no país, se caracteriza pela dispersão de suas poucas publicações. De fato, essa literatura não está acessível nem mesmo na principal base de dados da comunidade científica brasileira, o Diretório de Grupos de Pesquisa ${ }^{3}$. Em uma rápida consulta a essa base foi possível encontrar apenas 21 publicações, em cujo título ou pala- 
vras-chaves havia a expressão "gênero e ciência", todas elas publicadas por instituições acadêmicas/ científicas em periódicos de circulação nacional. Esse dado sugere pelo menos duas alternativas: ou (a) há poucos estudos e estu diosos nessa temática no Brasil ou (b) há muitos estudos e estudiosos nessa temática no Brasil, mas que estão fora da academia e/ ou não utilizam essa ferramenta (a base de dados) para tornar acessível a informação sobre seus estudos.

D entre os esforços (muitos deles pessoais) realizados para que esses estudos se fortificassem no país, destaca-se o pioneirismo do N úcleo de Estudos sobre a M ulher. C riado em fins dos anos de 1980, na Pontifícia U niversidade C atólica do Rio de J aneiro, esse núcleo estimulou a criação de novos núcleos no país e realizou diversas pesquisas e estudos sobre ciência e gênero, alguns dos quais estão reunidos em 0 laboratório de Pandora (Fanny, 2002), livro escrito por Fanny Tabak, fundadora do $\mathrm{N}$ úcleo e, sem dúvida, um dos expoentes desses estudos no país.

D entre os poucos estudos brasileiros publicados em periódicos científicos, destaco dois que utilizaram dados objetivos para pautar a discussão sobre alguns aspectos da temática da mulher na ciência, são eles: A construção social da produçãocientífica por mulheres(Velho, 1998) eTheC ontribution of Women in Brazilian Science: A CaseStudyin A stronomy, I mmunol ogy and O ceanography (L eta, 2003). $\mathrm{N}$ o primeiro estudo, os autores analisaram e discutiram a participação das mulheres no corpo docente, em cargos administrativos e na produção científica de alguns institutos da $U$ niversidade de $C$ ampinas. D entre a evidências, os autores encontraram que as mulheres na U nicamp ainda são minoria em algumas áreas, estão concentradas em outras e avançam lentamente na carreira científica. Em relação ao outro estudo, os autores mostraram que a produtividade de mulheres cientistas é proporcional à participação delas nas áreas anal isadas, indicando, portanto, que no Brasil, pelo menos nessas áreas, é mito a afirmativa de que mulheres cientistas produzem menos que homens.

\section{A recente participação da mulher na ciência brasileira}

A pesar de ainda preocupante, o quadro atual da participação das mulheres na ciência mundial difere, em boa parte dos países, daquele apresentado por Rossi (1965) para os EU A nos anos de 1950-1960 e comum a todos os países naquele momento (certamente alguns apresentavam maiores diferenças).

U m recente estudo da U nesco ( $M$ cgregor e $\mathrm{H}$ arding, 1996) mostrou que a participação de mulheres em instituições de educação superior tem crescido de forma significativa nas décadas de 1970, 1980 e 1990 em países da América L atina, Ásia e Europa O cidental. A pesar de não ser verdadeiro para todos os países (não há mudança no quadro, principalmente nos países da África), esse crescimento aponta para uma maior entrada de mulheres no sistema de $C \& T$, se considerarmos essas instituições, as universidades, como aquelas responsáveis por grande parte da ciência mundial. 
N o Brasil, a expansão da comunidade científica e da ciência faz parte da história recente do país ${ }^{4}$. A té o século XX, o número de instituições voltadas para a ciência era muito limitado e foi no final dos anos de 1960, com a edição do Plano Estratégico de Desenvolvimento $\mathrm{N}$ acional, que a questão científica e tecnológica surgiu como presença constante no planejamento nacional.

A pesar da recente institucionalização da ciência brasileira, foi também nos anos de 1980 e 1990 que as mulheres brasileiras aumentaram sua participação no setor. A falta de dados sistemáticos no Brasil sobre a formação e o perfil dos recursos humanos na educação superior e na ciência, assim como a falta de dados sobre o financiamento do setor dificultam muito a contextualização dessa discussão. M as fato é que, aos olhos, principalmente, dos mais "seniores", é evidente a mudança na universidade brasileira no que diz respeito à freqüência de mulheres: diferente de algumas poucas décadas atrás, elas hoje são a maioria em boa parte dos cursos de graduação e de pós-graduação do país. A Tabela 1 apresenta os totais de estudantes do sexo feminino, matriculadas em al guns cursos de graduação da U FRJ em diferentes momentos.

Tabela 1

Evolução do número de estudantes do sexo feminino, matriculadas na U niversidade Federal do Rio de J aneiro.

\begin{tabular}{|c|c|c|c|c|c|c|c|c|c|c|c|}
\hline \multirow[t]{2}{*}{ Centros } & \multirow[t]{2}{*}{ Cursos } & \multicolumn{2}{|c|}{1977} & \multicolumn{2}{|c|}{1982} & \multicolumn{2}{|c|}{1985} & \multicolumn{2}{|c|}{1990} & \multicolumn{2}{|c|}{ 2003\# } \\
\hline & & $\mathbf{N}$ & $\%$ & $\mathbf{N}$ & $\%$ & $\mathbf{N}$ & $\%$ & $\mathbf{N}$ & $\%$ & $\mathbf{N}$ & $\%$ \\
\hline \multirow[t]{3}{*}{ CT } & Civil & 15 & 12,3 & 5 & 21,7 & 3 & 20,0 & 5 & 21,7 & & \\
\hline & Elétrica & 14 & 17,3 & 1 & 11,1 & 9 & 3,0 & 14 & 4,5 & & \\
\hline & Química & 78 & 33,6 & 55 & 26,4 & 83 & 40,3 & 81 & 39,0 & & \\
\hline \multirow[t]{3}{*}{ CCMN } & Matemática & 92 & 1,3 & 65 & 40,3 & 73 & 39,0 & 70 & 36,0 & & \\
\hline & Física & 37 & 30,3 & 23 & 20,2 & 22 & 21,1 & 19 & 18,6 & & \\
\hline & Química & 35 & 49,3 & 26 & 52,0 & 24 & 52,1 & 30 & 67,0 & & \\
\hline \multirow[t]{3}{*}{ CCS } & Medicina & 103 & 35,0 & 91 & 49,0 & 81 & 46,0 & 101 & 62,0 & 48 & 51,6 \\
\hline & Odontologia & 35 & 55,0 & 46 & 58,2 & 37 & 53,0 & 44 & 60,3 & 32 & 86,5 \\
\hline & Biologia & 75 & 60,0 & 81 & 59,5 & 53 & 47,7 & 66 & 59,0 & & \\
\hline
\end{tabular}

\# O s totais de estudantes matriculados em 2003 foram obtidos com a Secretaria de Graduação do D epto de Bioquímica M édica e referem-se apenas aos estudantes do 20 semestre matriculados na disciplina de Bioquímica.

Fonte: Adaptado de Fanny (2002). O s percentuais referem-se à fração que as estudantes do sexo feminino representam no total de estudantes matriculados em cada um dos cursos nos respectivos anos.

O s dados da U FRJ apontam mudanças na freqüência de mulheres em alguns cursos tradicionalmente ocupados por homens, são eles: engenharia civil, engenharia química (da área tecnológica), química (da área de exatas) e medicina ( da área de saúde). Essa tendência sugere que em futuro não muito distante, profissões de maior reconhecimento, mais bem remuneradas e de maior status social contarão com expressiva e/ ou majoritária presença feminina. 
D ados mais recentes sobre 0 alunado das universidades brasileiras mostram que as mulheres já representam a maior fração entre os estudantes matriculados e concluintes. E $m$ 2001, elas representavam 56,3\%do total de matrículas (3.030.754) e $62,4 \%$ do total de concluintes no ensino universitário (I nep, 2003).

Vale destacar que apesar do aumento de mulheres freqüentando os cursos universitários e obtendo títulos universitários, as mulheres ainda representavam, em 1996, 28,5\%do total da população economicamente ativa, com vinte anos ou mais, das regiões metropolitanas de Recife, Salvador, Belo $\mathrm{H}$ orizonte, Rio de J aneiro, São Paulo e Porto Alegre (IBGE, 2003).

A maior presença de mulheres na academia certamente facilitou o contato, 0 acesso e a incorporação delas aos quadros das universidades brasileiras. A Figura 1 apresenta a admissão de docentes, no perío do de 1930 a 2003, na maior universidade pública do país, a U niversidade de São Paulo, e responsável por cerca de $25 \%$ da produção científica brasileira (Leta, 2002).

Figura 1

Admissão de docentes na U nivesidade de São Paulo segundo o sexo.

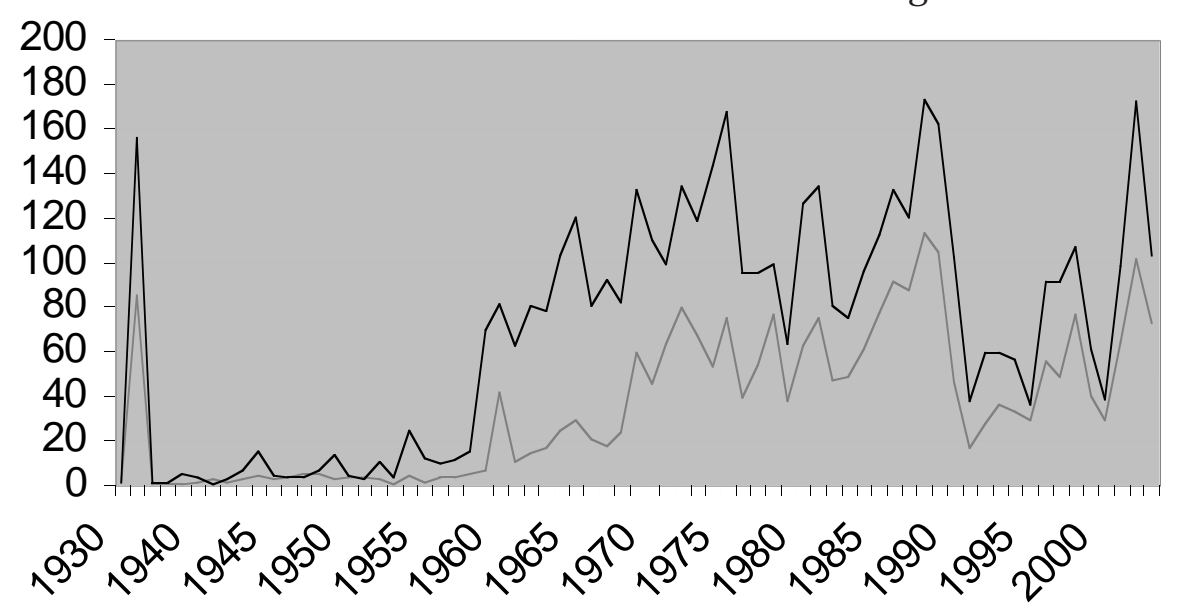

- Feminino - Masculino

A figura mostra picos de admissão ao longo das décadas, que foram momentos de contratações volumosas. Além disso, observa-se facilmente que a incorporação de homens e mulheres ao quadro de docentes da U SP durante as décadas de 1960 e 1970 era bastante desigual. Esse quadro, no entanto, muda nas décadas seguintes, resultado da maior demanda de mulheres no mercado de trabalho acadêmico, que, no caso específico da U SP, exigia docentes com maiores titulações. Assim, não se trata apenas de um crescimento de demanda, mas um crescimento de uma demanda mais bem qualificada. A pesar da mudança de quadro, é importante destacar que as mulheres ainda são minoria no sistema universitário público e representam hoje, em 2003 , 34\% do total dos docentes 
ativos da U SP ${ }^{5}$. E sse dado, associado à informação do IBGE sobre força de trabalho aponta, portanto, que as mudanças e a inserção real da mulher no mercado de trabalho, que inclui o setor de ciência e tecnologia, ainda não aconteceram de fato em nosso país.

A incorporação de mulheres no sistema de ciência e tecnologia também pode ser verificada a partir da distribuição de bolsas concedidas por agências de governo que financiam o setor, como é o caso do CN Pq. I mportante lembrar aqui o grande esforço do governo federal, nos anos de 1980 e 1990, em financiar os programas de formação de recursos humanos para o setor. As informações mostradas nas Tabelas 2 e 3 foram extraídas do CN Pq, diretamente ou por meio do Diretório de Grupos de Pesquisa. M uito embora o CN Pq organize dados em séries históricas, a informação sobre o sexo dos pesquisadores só aparece consolidada para os últimos anos. Q uando observamos a evolução do sexo dos pesquisadores brasileiros cadastrados nessa base (Tabela 2) é possível identificar uma tendência de crescimento na fração de mulheres que estão assumindo posições de pesquisadores (associados ao grupo de pesquisa) e pesquisadores-líderes (são os coordenadores/ responsáveis pelo grupo de pesquisa) nos grupos de pesquisa, indicando uma maior inserção delas no sistema não apenas como estudantes, mas como atores de maior reconhecimento e maior qualificação hierárquica.

Tabela 2 - D istribuição dos pesquisadores por sexo, 1997, 2000 e 2002.

\begin{tabular}{|l|c|c|c|c|c|c|}
\hline \multicolumn{4}{|c|}{ Pesquisadores } & \multicolumn{3}{c|}{ Pesquisadores líderes } \\
\hline Ano & Total & Masc, $\%$ & Fem,\% & Total & Masc, $\%$ & Fem,\% \\
\hline 1997 & 33.675 & 58,0 & 42,0 & 10.474 & 62,7 & 37,3 \\
\hline 2000 & 48.781 & 56,0 & 43,7 & 16.456 & 60,6 & 39,4 \\
\hline 2002 & 56.891 & 54,3 & 45,7 & 21.062 & 59,3 & 40,7 \\
\hline
\end{tabular}

Fonte: Diretório de Grupos de Pesquisa do CN Pq, censos de 1997, 2000 e 2002.

É razoável prever que, no próximo senso, as frações de pesquisadores homens e mulheres se aproximem ainda mais e, mais à frente, também se aproximem as frações referentes aos pesquisadores-líderes, posição de maior destaque e reconhecimento no meio científico e acadêmico.

Esse aumento de pesquisadores do sexo feminino nos grupos de pesquisa brasileiros é fruto da maior entrada de mulheres no sistema de $C \& T$. M ais estudantes do sexo feminino nos cursos de graduação e nos programas de pós-graduação possibilitaram a maior demanda delas por posições de maior hierarquia no sistema. A distribuição das diferentes modalidades de bolsas concedidas pelo $\mathrm{CN} \mathrm{Pq}{ }^{6}$, segundo o sexo dos contemplados, está apresentada na Tabela 3. O bserva-se que a proporção de bolsistas mulheres cresce nas diferentes modalidades, mas diminui na medida em que cresce o nível hierárquico da bolsa. Esse é um indicativo de que uma parcela das mulheres que passam pelos primeiros estágios de 
capacitação e treinamento para as atividades científicas, se "perdem" ao longo desse caminho ou simplesmente não ganham o reconhecimento dos pares através da concessão de suas bolsas. A comparação dos dados apresentados nas T abelas 2 e 3 sugere que pode existir algum tipo de discriminação no sistema de concessão de bolsas, especificamente na questão das bolsas de produtividade, as de maior nível hierárquico. Segundo os dados do CN Pq, em 2002 havia para cada pesquisador, 0,84 pesquisadora cadastrada no D iretório de Grupos de Pesquisa; essa relação diminui muito na concessão da bolsa de produtividade: para cada pesquisador que é contemplado com essa bolsa, há 0,48 pesquisadora na mesma situação.

Tabela 3

D istribuição de bolsas do CN Pq segundo a modalidade e sexo do contemplado, 2001 e 2002.

\begin{tabular}{|c|c|c|c|c|}
\hline Modalidade da bolsa & Feminino & Masculino & Total de bolsas & \% feminino \\
\hline Iniciação científica: & & & & \\
\hline 2001 & 7911,5 & 6506,2 & 14417,7 & 54,87 \\
\hline 2002 & 7737 & 6303,8 & 14040,8 & 55,10 \\
\hline 2001 & & & & \\
\hline 2002 & 2950,4 & 2842,8 & 5793,2 & 50,93 \\
\hline Mestrado: & 2956,8 & 2635,9 & 5592,7 & 52,87 \\
\hline 2001 & 2836,9 & 3000,3 & 5837,2 & 48,60 \\
\hline 2002 & 2774,7 & 2960,1 & 5734,8 & 48,38 \\
\hline Doutorado: & & & & \\
\hline 2001 & 140,8 & 154,1 & 294,9 & 47,74 \\
\hline Recém-Doutor: & 187,2 & 189,2 & 376,4 & 49,73 \\
\hline Pesquisa: & & & & \\
\hline 2001 & 2457,1 & 5204,2 & 7661,3 & 32,07 \\
\hline 2002 & 2503,4 & 5259,8 & 7763,2 & 32,25 \\
\hline
\end{tabular}

Fonte: CN Pq (2003).

\section{C ontrastes e discriminação?}

A pesar do crescimento da participação de mulheres nas atividades de $C \& T$, as chances de sucesso e reconhecimento na carreira ainda são reduzidas. I sso está traduzido na questão da concessão das bolsas de produtividade (Tabela 3) e na participação das mulheres em cargos administrativos da U niversidade Federal do Rio de J aneiro, a maior universidade do sistema federal, como mostra a Tabela 4. O s dados indicam que as mulheres representam hoje, em 2003, 43,7\% do total de docentes da universidade. No entanto, elas ocupam somente $24 \%$ dos cargos administrativos da instituição. Vale destacar que nem mesmo nos centros onde elas são maioria, como no Centro de Filosofia e Ciências $\mathrm{H}$ umanas e no C entro de L etras e Artes, o quadro se reverte. 
Tabela 4 - D istribuição do corpo docente da U FRJ segundo o sexo, ano 2003.

\begin{tabular}{|l|c|c|c|c|}
\hline & \multicolumn{2}{|c|}{$\begin{array}{c}\text { Corpo } \\
\text { docente }\end{array}$} & \multicolumn{2}{c|}{$\begin{array}{c}\text { Cargos } \\
\text { administrativos }\end{array}$} \\
\hline Centro & Fem. & Masc. & Fem. & Masc. \\
\hline Centro de Ciências Jurídicas e Econômicas & 60 & 207 & 1 & 4 \\
\hline Centro de Ciências Matemáticas e da Natureza & 137 & 311 & 2 & 16 \\
\hline Centro de Ciências da Saúde & 540 & 545 & 4 & 11 \\
\hline Centro de Filosofia e Ciências Humanas & 291 & 198 & 7 & 14 \\
\hline Centro de Letras e Artes & 270 & 249 & 5 & 10 \\
\hline Centro de Tecnologia \# & 59 & 236 & 3 & 13 \\
\hline Fórum de Ciência e Cultura & 34 & 46 & 1 & 5 \\
\hline Total & $\mathbf{1 . 3 9 1 ^ { * }}$ & $\mathbf{1 7 9 2 *}$ & $\mathbf{2 3}$ & $\mathbf{7 3}$ \\
\hline
\end{tabular}

Fonte: SIGM A/ U FRJ (2003).

* O s totais de docentes são maiores do que o apresentado na tabela, pois não foi possível estabelecer o sexo de 45 nomes. \# 0 total de docentes no Centro de Tecnologia, segundo o SI GM A/ U FRJ, é de 502, no entanto, o sistema só tem o registro de 298.

O utro indicativo, que se soma à reduzida participação de mulheres em cargos administrativos das principais instituições de $C \& T$ do país, é a eleição de-las para a A cademia B rasileira de Ciências (Tabela 5). D entre os acadêmicos titulares, ativos em 2003, as mulheres representam menos de $10 \%$ do total, fração muito inferior do que elas representam hoje na ciência brasileira (Tabela 2). N as Engenharias e nas Ciências da Saúde não há nenhuma mulher entre os acadêmicos. No caso dessas áreas, bem como nas de Física e M atemática, a ausência de mulheres entre os acadêmicos reforça ainda mais o estereótipo masculino associado a essas áreas. M as, quando se observam os acadêmicos associados, uma posição certamente de menor prestígio, elas são mais representativas, representando cerca de $40 \%$ do total.

Tabela 5 - Distribuição dos cientistas titulares e associados na Academia Brasileira de Ciência segundo a área e o sexo, 2003.

\begin{tabular}{|l|c|c|c|c|c|c|}
\hline \multicolumn{4}{|c|}{ Acadêmicos titulares } & \multicolumn{3}{c|}{ Acadêmicos associados } \\
\hline Grande Área & Feminino & Masculino & Total & Feminino & Masculino & Total \\
\hline Agrárias & 1 & 11 & 12 & & 1 & 1 \\
\hline Biológicas & 3 & 17 & 20 & 4 & 5 & 9 \\
\hline Biomédicas & 10 & 86 & 96 & 11 & 19 & 30 \\
\hline C. da Terra & 1 & 35 & 36 & 4 & 11 & 15 \\
\hline Engenharias & & 17 & 17 & & 3 & 3 \\
\hline Física & 2 & 60 & 62 & 2 & 11 & 13 \\
\hline Humanas & 4 & 10 & 14 & - & - & - \\
\hline Matemática & 1 & 42 & 43 & 1 & 5 & 6 \\
\hline Química & 4 & 36 & 40 & 3 & 7 & 10 \\
\hline Saúde & & 13 & 13 & & 1 & 1 \\
\hline Total & 26 & $\mathbf{3 2 6}$ & $\mathbf{3 5 3}$ & $\mathbf{2 5}$ & $\mathbf{6 3}$ & $\mathbf{8 8}$ \\
\hline
\end{tabular}

Fonte: ABC (2003). 
Esse fenômeno que se refere às chances remotas que as mulheres têm de ascender profissionalmente, de assumir maiores responsabilidades e ganhar reconhecimento e também de obter qualificações mais especializadas foi denominado, por M argaret Rossiter, na década de 1980, de segregação hierárquica (Schienbinger, 2001). No caso da atividade científica, diversos estudos têm buscado fatores que expliquem as razões pelas quais as mulheres não avançam, esses fatores vão desde a falta de controle emocional das mulheres, que as tornam menos resistentes às pressões freqüentes dos cargos de comando; à educação das mulheres que não Ihes favorece o desenvolvimento do fator agressividade, fundamental nesses cargos e, de um outro ponto de vista; às estruturas das instituições acadêmicas e científicas que são dominadas por homens, fato que reforça 0 estereótipo masculino como o único apto a assumir tais cargos e posições.

Vale dizer que segregação hierárquica (ou vertical) não é exclusividade de países não desenvolvidos economicamente ou cuja consolidação da atividade acadêmico/ científica é ainda recente, como o Brasil. Dados da N ational Science Foundation (N SF, 1995), importante agência financiadora da ciência norte-americana, mostram que a representação de mulheres nas universidades dos EU A também cai conforme elas progridem nos níveis acadêmicos: em 1995, elas representavam cerca de $46 \%$ entre os instrutores, $35 \%$ entre os professores assistentes, $25 \%$ entre os professores asso ciados e $11 \%$ entre os professores titulares, aqueles de maior prestígio e reconhecimento entre os pares.

\section{Johanna D öbereiner:}

\section{um perfil de destaque na ciência brasileira}

A pesar dos mitos e discriminações, algumas mulheres alcançam statuse destaque na nacional e internacional, tal como foi J ohanna Döbereiner, falecida em outubro de 2000, uma unanimidade no meio científico ${ }^{7}$.

$N$ ascida na então C hecoslováquia em 1924, D öbereiner migrou para o Brasil em 1951, quando começou a trabalhar para o M inistério da Agricultura, no L aboratório de M icrobiologia de Solos. Em 1956, tornou-se cidadã brasileira e, pouco tempo depois, matriculou-se no curso de pós-graduação de microbiologia de solos da U niversidade de Wisconsin (EU A), obtendo o título de mestre em 1963.

Ao retornar ao Brasil, ela iniciou um programa de pesquisas so bre os aspectos limitantes da fixação biológica de nitrogênio em plantas tropicais, como a soja. Ao longo de seus estudos, ela descobriu a íntima associação de determinadas bactérias com plantas e percebeu que elas, as bactérias, agiam como uma espécie de adubo natural. Q uando colocadas junto às sementes da soja, essas bactérias estimulavam o surgimento de estruturas nas raízes que facilitavam a maior incorporação do nitrogênio do ar para as plantas. Esses estudos permitiram a redução a zero dos custos com adubos nitrogenados uma vez que a bactéria fornecia ("gratuitamente") esse elemento diretamente à planta. O s estudos liderados pela D ra D öbereiner permitiram uma economia gigantesca na lavoura da soja, 
com a não adubação nitrogenada (estima-se em U S\$ 1,5 bilhão por ano), tornando o país um dos líderes na produção mundial de soja. Além disso, esses estudos ajudaram a preservar o meio ambiente, pois muitos dos adubos anteriormente adicionados às lavouras continham elementos nocivos ao meio ambiente.

J ohanna $D$ öbereiner foi merecedora de diversos prêmios e distinções dentro e fora do país, tais como, Cidadão H onorário do Rio de J aneiro; homenagem no 12th International C ongress of Soil Science, N ova D elhi, Í India; prêmio Vállee de Biotecnologia, Fenabio, 1988; medalha Julio 11 da Sociedade M exicana de M icrobiologia; O rdem de M érito do Tribunal Superior do Trabalho, Brasília, 1991; Inter-American Sugar C ane Seminars, M iami, Flórida; TWAS $M$ edal and Lecture A warded, 1995; homenagem da E mbrapa, C entro N acional de Pesquisa de Recursos Genéticos e Biotecnologia; prêmio por Excelência da E mbrapa, Téc-nico Científico, 1997; homenagem da Embrapa, CPAA, 1997; The 20 th Century A ward for A chievement, 1997; Prêmio Carioca H onorário, O Globo; O rdem de M érito Científico. Além desses, ela foi membro titular da $A B C$, chegando ao cargo de vice-presidente em 1995; recebeu a O rdem N acional do Mérito do Go-verno Brasileiro, poucas vezes concedidas às mulheres cientistas; e em 1997, foi indicada para o Prêmio N obel de Q uímica, mas infelizmente não foi contemplada.

J ohanna D öbereiner foi, sem dúvida, uma pesquisadora brilhante, que associou de forma única a pesquisa básica com as necessidades reais do país e que talvez o fato de ter sido mulher tenha sido decisivo para a escolha de sua linha de pesquisa nos anos de 1960, que propunha, na verdade, competir com uma indústria muito poderosa. À época, eram poucos os cientistas que a estimularam a seguir, mas sua percepção feminina a fez trilhar nessa linha de pesquisa, o que lhe garantiu tamanho sucesso e reconhecimento.

\section{Comentários finais}

As estatísticas mostradas anteriormente apontam que, se por um lado, as mulheres têm participado cada vez mais das atividades de $C \& T$ no Brasil, por outro, elas ainda não avançam em cargos e posições de destaque e reconhecimento, com raras exceções, como a D ra. Döbereiner. M itos, discriminações, o que está por trás desse quadro? O s números certamente não dão conta de responder a essa questão, mas fornecem medidas objetivas do status das mulheres na ciência em nosso país: elas ainda estão em desvantagem num sistema controlado predominantemente por homens. Q uantas mulheres são reitoras de universidades públicas (as mais importantes para o sistema de $C \& T$ ) ? Q uantas ocupam altos cargos no M inistério de C iência e Tecnologia ou em suas agências, como 0 CN Pq? Q uantas estão nos comitês científicos que decidem para onde e para quem vão os recursos e bolsas? As respostas a essas (e a muitas outras) mostrarão valores que podem variar, mas para todas encontraremos uma presença muito reduzida de mulheres nesses postos. 


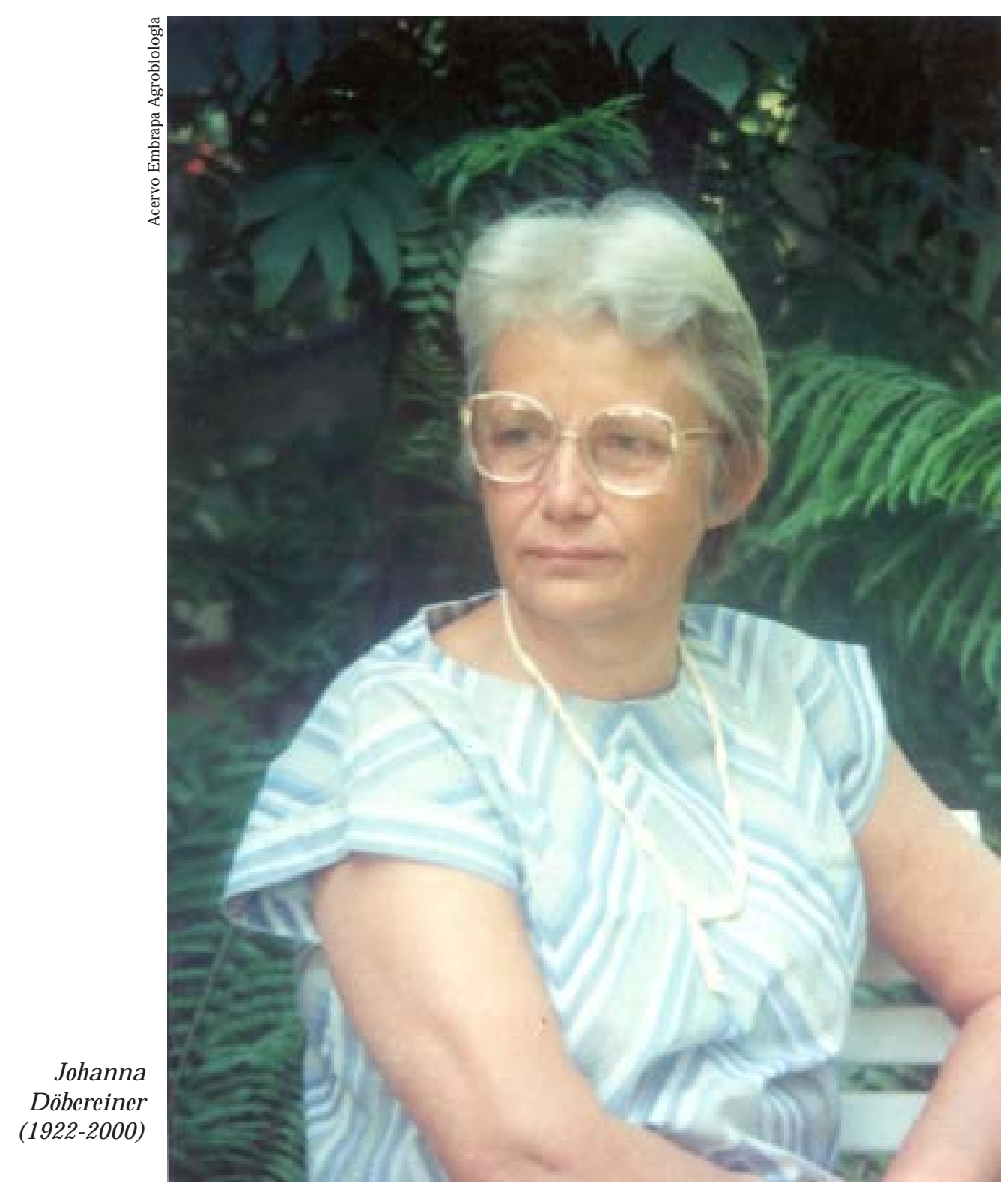

Fato é que se nosso país pretende desenvolver-se economicamente, é necessário um investimento massivo em setores como educação e $C \& T$. Além disso, torna-se fundamental estimular que metade da nossa força de trabalho participe ativamente desses setores estratégicos para o país. A participação crescente de mulheres no ensino superior aponta para mudanças na inserção desse contingente no mercado de trabalho, mas a baixa proporção de mulheres em al gumas áreas científicas (Tabak, 2002) e em cargos de liderança é um indício do desperdício de recursos humanos que, se bem qualificados, podem contribuir significativamente para um maior desenvolvimento do sistema, dando a ele maior diversidade em valores, condutas, ações... 


\section{N otas}

1 D etalhes sobre essa discussão poderão ser encontrados nas referências: Schienbinger (2001) e Pnina (1996).

2 D etalhes sobre essa discussão poderão ser encontrados nas referências: Schienbinger (2001), Soares (2001), H anson (1996), M orse (1995), Stolte-H eiskanen (1991) e $\mathrm{N}$ ature $\mathrm{D}$ ebates.

3 O rganizado pelo CN Pq (um dos principais órgãos de fomento à ciência do governo federal) desde 1993, o Diretório de Grupos de Pesquisa reúne informações sobre os grupos de pesquisa, sobre os pesquisadores e seus estudantes e sobre sua produção científica e tecnológica. Tem, portanto, o importante papel de disseminar o conhecimento científico, humanístico e artístico produzido, principalmente, nas instituições acadêmicas e científicas do país. Acesso através da página: http:/ / lattes.cnpq.br/ diretorio/

4 Para detalhes sobre a institucionalização da ciência brasileira, sugere-se a leitura de Stepan (1976) e Schwartzman (1978).

$5 \mathrm{D}$ ados fornecidos pelo $\mathrm{D}$ epartamento de Recursos $\mathrm{H}$ umanos da U niversidade de São Paulo, em agosto de 2003.

6 Bolsa de I niciação Científica concedida para os estudantes dos cursos de graduação; bolsas de M estrado e D outorado concedidas para os estudantes matriculados nos cursos de pós-graduação, no nível de mestrado e doutorado respectivamente; bolsa de Recém-doutor concedida para aqueles que já têm o título de doutor, porém não têm vínculo empregatício com nenhuma instituição; bolsa de Produtividade de pesquisa concedida para os pesquisadores com maior desempenho científico em sua área de atuação (trata-se, na verdade, de uma complementação salarial).

7 Ver página da E mbrapa: http:/ / www.cnpab.embrapa.br/ instituicao/ johanna.html.

\section{Referências bibliográficas}

ABC , A cademia Brasileira de Ciências. O rganização: A cadêmicos. Consulta on-line, ago. 2003, página: http:/ / www.abc.org.br/

CN Pq, Conselho N acional de D esenvolvimento Científico e Tecnológico. Estatísticas: I nvestimentos em C\& T. C onsulta on-line, set. 2003, http:/ / www.cnpq.br/ servicos/ estatisticas/ index.htm

H AN SO N , S. L. L ost Talent: Women in theSciences Temple U niversity Press, Philadelphia, U SA, 1996.

IBGE , I nstituto Brasileiro de G eografia e E statística. Estatísticas em E ducação e trabaIho, senso de 1996. Consulta on-line, set. 2003, http:/ / www.ibge.gov.br

I NEP/ MEC, Instituto N acional de Estudos e Pesquisas Educacionais Anísio Teixeira. EDU D ATABRASI L - Sistema de Estatísticas E ducacionais. Consulta on-line, set. 2003, página: http:/ / www.edudatabrasil.inep.gov.br/

LETA, L. e LEWISON, G. "The Contribution of Women in Brazilian Science: A Case Study in Astronomy, I mmunology and O ceanography". Scientometrics 57, 2003, pp. 339-353. 
LETA, J. e MENEGH INI, R. "Produção Científica". Em Indicadores de Ciência, Tecn ologia el novação em do Estado de São Paulo - 2001, São Paulo, Fapesp, 2002.

LO PES, M. M. “A ventureiras” nas ciências. Refletindo sobre gênero ehistória das ciências naturais no Brasil". Cadernos Pagu 10, 1998, pp. 345-368.

M cGREGOT, E. e HARDING, S. "Science By Whom?" Em The Gender Dimension of Science And Technology. U nesco, World Science Report. 1996. H ttp:/ / Www.U nesco.O rg/ Science/ Publication/ Eng_Pub/ Gender.H tm

M ORSE, M. Women Changing Science. Voices from a Filed in Transition. N ew York, Plenum Press, 1995.

N ature D ebates. Www.nature.com/ nature/ debates/

PN I N A, G. "Women in M odern Scientific Research: A H istorical View". Em TheGender Dimension of Science and Technology. U nesco, World Science Report. 1996. http:/ / www.unesco.org/ science/ publication/ eng_pub/ gender.htm

ROSSI, A. S. "Women in Science: Why so Few? Social and Psychological Influences Restrict Women's Choice and Pursuit of Carrers in Science", Science 148, 1965, pp. 1196-1202.

SCH IEN BI N GER, L. O feminismo mudou a ciência? Bauru, Edusc, 2001.

SCH WARTZM AN, S. Struggling to beBorn: TheScientific Communityin Brazil. M inerva, vol. XVI, 1978, pp. 545-580.

SIGM A/ U FRJ, Estrutura acadêmica: Docentes dos Centros. Consulta on-line, ago. 2003, http:/ / www.sigma.ufrj.br/ site/ foco/ index.htm

SO ARES, T. M . "M ulheres em ciência e tecnologia: ascensão limitada”. Química N ova 24, 2001, pp. 281-285.

STEPAN, N. Gênese e evolução da Ciência brasileira. Rio de Janeiro, Artenova, 1976.

STOLTE-HEINSKANEN, V. Women in Science. Token Women or Gender Equality? International Social Science Countil/ U nesco, 1991.

TABAK, F. O Laboratório de Pandora. Rio de Janeiro, Garamond, 2002.

VELHO, L e LEÓN, E. "A construção social da produção científica por mulheres”. Cadernos Pagu 10, 1998, pp. 309-344.

RESUMO - HISTO RICAM ENTE, a ciência sempre foi vista como uma atividade realizada por homens e foi somente após a segunda metade no século XX que ocorreram mudanças nesse quadro. 0 presente estudo mostra o crescimento da participação feminina em alguns cursos de graduação da U FRJ (inclusive em cursos tradicionalmente ocupados por homens), nos grupos de pesquisas cadastrados no CN Pq, como bolsistas do CN Pq e no quadro de docentes da U SP. O estudo também mostra que, apesar da maior participação no sistema brasileiro de $C \& T$, as mulheres têm chances menores de sucesso e ascensão na carreira: são menos contempladas com bolsas de produtividade do CN Pq, estão sub-representadas nos cargos administrativos da U FRJ e entre os acadêmicos da Academia Brasileira de Ciências. 
A BSTRACT - HISTO RICALLY science has been pointed out as a male activity. U nfortunatelly, this portrait has changed only after $2^{\text {nd }}$ World War. The present study shows data of female participation within some undergraduate courses at U FRJ (including some which are traditionally carried by males), within the research groups registered in the $\mathrm{CN} \mathrm{Pq}$ database and within the teacher's staff of U SP. The study also shows that, although females are increasing within the Brazilian system of science \& technology, they seem to have less chances to ascend in career: they are less granted with CN Pq fellowship, they are underrepresented within the academic positions at U FRJ and within the members of the Brazilian Academy of Sciences.

J acqueline Leta é professora-adjunta do D epartamento de Bioquímica M édica do I nstituto de Ciências Biomédicas (ICB) da U niversidade Federal do Rio de J aneiro (U FRJ), onde coordena o Programa de Educação, G estão e D ifusão.

Texto recebido e aceito para publicação em 16 de setembro de 2003. 